\title{
On Expectations-Driven Business Cycles in Economies with Production Externalities: A Comment*
}

\author{
Jang-Ting $\mathrm{Guo}^{\dagger}$ \\ University of California, Riverside \\ Anca-Ioana Sirbu ${ }^{\ddagger}$ \\ Richard M.H. Suen ${ }^{\S}$ \\ University of California, Riverside
}

September 13, 2010

\begin{abstract}
Eusepi (2009, International Journal of Economic Theory 5, pp. 9-23) analytically finds that a one-sector real business cycle model may exhibit positive co-movement between consumption and investment when the equilibrium wage-hours locus is positively-sloped and steeper than the household's labor supply curve. However, we show that this condition does not imply expectations-driven business cycles will emerge in Eusepi's model. Specifically, a positive news shock about future productivity improvement leads to an aggregate recession whereby output, employment, consumption and investment all fall in the announcement period.
\end{abstract}

Keywords: Expectations-Driven Business Cycles; Production Externalities.

JEL Classification: C62; E32.

\footnotetext{
${ }^{*}$ We would like to thank R. Anton Braun, Juin-Jen Chang, Been-Lon Chen, Hung-Ju Chen, Yu-Chin Chen, Minchung Hsu, Yi-Chan Tsai, and seminar participants in the 2010 Taipei International Conference on Growth, Trade and Dynamics, Academia Sinica (Taiwan), and the 10th Society for the Advancement of Economic Theory Conference for helpful discussions and comments. Part of this research was conducted while Guo was a visiting research fellow of economics at Academia Sinica, whose hospitality is greatly appreciated. Of course, all remaining errors are our own.

${ }^{\dagger}$ Corresponding Author. Department of Economics, 3133 Sproul Hall, University of California, Riverside, CA, 92521, USA, 1-951-827-1588, Fax: 1-951-827-5685, E-mail: guojt@ucr.edu.

${ }^{\ddagger}$ Department of Economics, 3128 Sproul Hall, University of California, Riverside, CA, 92521, USA, 1-310866-1097, Fax: 1-951-827-5685, E-mail: anca.sirbu@email.ucr.edu.

${ }^{\S}$ Department of Economics, 3132 Sproul Hall, University of California, Riverside, CA, 92521, USA, 1-951827-1502, Fax: 1-951-827-5685, E-mail: mhsuen@ucr.edu.
} 


\section{Introduction}

Starting with the work of Beaudry and Portier (2004, 2007), it is now well known that the standard one-sector real business cycle (RBC) model with a constant returns-to-scale technology and perfectly competitive markets does not display expectations-driven business cycles. Specifically, this model predicts that current consumption and current investment will move in the opposite direction after agents receive a signal of future productivity improvement. In a recent publication of this journal, Eusepi (2009) resolves this issue by introducing external effects to firms' production process. He analytically finds that the one-sector RBC model can exhibit positive co-movement between consumption and investment when the degree of production externalities is sufficiently strong to yield a positively-sloped equilibrium wage-hours locus which is steeper than the household's labor supply curve. However, this comment shows that solving the co-movement problem does not imply expectations-driven business cycles will emerge in one-sector RBC models. As clearly stated by Beaudry and Portier (2004, p. 1189), this type of cyclical fluctuations is characterized by "a joint increase of consumption, investment, output and hours following a good news." In a calibrated version of the Eusepi model, our quantitative analysis demonstrates that in response to the favorable news of an upcoming technological progress, output, employment, consumption and investment all fall during the announcement period. Intuitively, a positive expectational shock causes a leftward shift of the upward sloping equilibrium wage-hours locus, which will lower the expected future real wage and hours worked. This in turn reduces the household's expected lifetime income and leads to a decrease in current consumption because of a negative wealth effect. Since consumption and investment are moving in the same direction within Eusepi's (2009) model economy, an aggregate recession takes place after a good news is announced. This result remains qualitatively robust under a generalized constant-relative-risk-aversion preference formulation in consumption, which is maintained to be additively separable from labor hours in the household utility.

\section{The Economy}

This section first briefly describes the decentralized version of Eusepi's (2009, section 2) onesector real business cycle model with an aggregate production function that exhibits increasing returns-to-scale. We also follow his notations as closely as possible to facilitate comparison. There is a continuum of identical competitive firms, with the total number normalized to one. Each firm produces output $y_{t}$ using the following Cobb-Douglas production function: 


$$
y_{t}=x_{t} A_{t} k_{t}^{\alpha} h_{t}^{1-\alpha}, \quad 0<\alpha<1
$$

where $A_{t}$ represents the total factor productivity, and $k_{t}$ and $h_{t}$ are capital and labor inputs, respectively. In addition, $x_{t}$ denotes productive externalities that are taken as given by the individual firm, and postulated to take the form

$$
x_{t}=\left(K_{t}^{\alpha} H_{t}^{1-\alpha}\right)^{\eta}, \eta>0
$$

where $K_{t}$ and $H_{t}$ are the economy-wide levels of physical capital and labor services. In a symmetric equilibrium, all firms make the same decisions such that $k_{t}=K_{t}$ and $h_{t}=H_{t}$, for all $t$. As a result, (2) can be substituted into (1) to obtain the social technology that displays increasing returns-to-scale

$$
y_{t}=A_{t} k_{t}^{\alpha(1+\eta)} h_{t}^{(1-\alpha)(1+\eta)},
$$

where $\alpha(1+\eta)<1$ to rule out sustained economic growth. Under the assumption that factor markets are perfectly competitive, the first-order conditions for the firm's profit maximization problem are given by

$$
\begin{gathered}
r_{t}=\alpha \frac{y_{t}}{k_{t}}, \\
w_{t}=(1-\alpha) \frac{y_{t}}{h_{t}},
\end{gathered}
$$

where $r_{t}$ is the capital rental rate and $w_{t}$ is the real wage.

The economy is also populated by a unit measure of identical infinitely-lived households, each has one unit of time endowment and maximizes a discounted stream of expected utilities over its lifetime

$$
E_{0} \sum_{t=0}^{\infty} \beta^{t}\left[\log c_{t}-\phi \frac{h_{t}^{1+\gamma}}{1+\gamma}\right], \quad 0<\beta<1, \quad \gamma \geq 0 \text { and } \phi>0,
$$

where $\beta$ is the discount factor, $c_{t}$ is consumption and $\gamma$ denotes the inverse of the intertemporal elasticity of substitution in labor supply. Households derive income from providing capital and labor services to firms. Hence, the budget constraint faced by the representative household is

$$
c_{t}+i_{t}=y_{t}=r_{t} k_{t}+w_{t} h_{t}
$$

where $i_{t}$ is gross investment that relates to the accumulation of capital stock through 


$$
k_{t+1}=(1-\delta) k_{t}+i_{t}, \quad k_{0}>0 \text { given, }
$$

where $\delta \in(0,1)$ is the capital depreciation rate.

The first-order conditions for the household's dynamic optimization problem are given by

$$
\begin{gathered}
\phi c_{t} h_{t}^{\gamma}=w_{t}, \\
\frac{1}{c_{t}}=\beta E_{t}\left[\frac{1}{c_{t+1}}\left(1-\delta+r_{t+1}\right)\right], \\
\lim _{t \rightarrow \infty} \beta^{t} \frac{k_{t+1}}{c_{t}}=0,
\end{gathered}
$$

where (9) is an intratemporal condition that equates the household's marginal rate of substitution between consumption and leisure to the real wage. Equation (10) is the standard Euler equation for intertemporal consumption choices, and (11) is the transversality condition.

Next, per Beaudry and Portier's (2004, Appendix A; 2007) temporary equilibrium approach, we use equations $(3),(5),(7)$ and (9) together with $k_{t}$ being pre-determined to obtain the analytical expression of $\frac{d c_{t}}{d i_{t}}$ as follows:

$$
\frac{d c_{t}}{d i_{t}}=\frac{1}{\frac{y_{t}}{c_{t}}\left[\frac{(1-\alpha)(1+\eta)}{(1-\alpha)(1+\eta)-1-\gamma}\right]-1},
$$

which governs the sign of co-movement between consumption and investment when period- $t$ goods and labor markets clear. It follows that $\frac{d c_{t}}{d i_{t}}>0$ if and only if $\frac{(1-\alpha)(1+\eta)}{(1-\alpha)(1+\eta)-1-\gamma}>\frac{c_{t}}{y_{t}}>0$. Since $\gamma \geq 0$, the preceding condition is satisfied when

$$
(1-\alpha)(1+\eta)-1>\gamma
$$

which states that the equilibrium wage-hours locus is positively sloped and steeper than the household's labor supply curve. Eusepi (2009, p. 13) points out that (13) is also a necessary (not sufficient) condition for our discrete-time model economy to display equilibrium indeterminacy as in Benhabib and Farmer (1994). Therefore, the theoretical conditions for a one-sector RBC model to exhibit positive co-movement between key macroeconomic variables and indeterminate equilibria are tightly connected. 


\section{Expectations-Driven Business Cycles}

This section quantitatively examines a calibrated version of the Eusepi model in response to agents' optimistic expectations about productivity growth, while maintaining saddle-path stability and equilibrium uniqueness. As in Beaudry and Portier (2004), the stochastic process for exogenous technology shocks fed into our numerical experiments are postulated as follows. The economy starts at its steady state in period zero. At period 1, households receive a signal that there will be a one-percent permanent increase in the total factor productivity from period 4 (denoted as $A_{4}$ ) onwards. However, in $t=4$ agents realize that this announced technological progress is not realized, hence there exists a forecast error in the household's expectations of future economic fundamentals. In addition, we adopt the following quarterly parameterization that is commonly used in the real business cycle literature: $\alpha=0.3, \beta=0.99, \gamma=0$ (i.e. indivisible labor), and $\delta=0.025$. Given the calibrated values of $\alpha$ and $\gamma$, the threshold level of production externalities that satisfies the necessary and sufficient condition for positive co-movement between consumption and investment, as in (13), is $\eta_{\min }=0.4286$.

Figure 1 presents the impulse response functions of our model economy in response to the above exogenous productivity process under $\eta=0.44$ for the purpose of clear illustration and $\phi=2.6226$ such that the steady-state hours worked are equal to $1 / 3$. Notice that although consumption and investment (as well as output and labor hours) are moving in the same direction as (12) and (13) together would predict, a positive expectational shock leads to an aggregate recession in $t=1$, and continues to last until period 4 when households realize that their forecast was incorrect. This result thus indicates that in sharp contrast to what Eusepi's (2009) work implies, a one-sector RBC model with sufficiently strong increasing returns in production does not display Pigou or expectations-driven business cycles which call for simultaneous expansions of consumption, investment, output and employment after the announcement of a good news is made.

Next, we provide economic intuitions behind the aggregate recession at period 1. Figure 2 depicts the labor market in $t=4$ with an upward sloping equilibrium wage-hours locus that intersects the labor supply curve from below. The equilibrium wage-hours locus can be obtained by taking logarithms on equation (5), while the labor supply curve can be obtained by taking logarithms on equation (9). When agents receive the news of an increase in total factor productivity, they anticipate that a higher $A_{4}$ causes the equilibrium wage-hours locus to shift leftward. The resulting excess supply for labor moves the equilibrium from $E$ to $E^{\prime}$, which will lower the expected real wage $w_{4}$ and hours worked $h_{4}$. As a consequence, the household expects a reduction in lifetime (labor) income, and hence chooses to decrease its consumption in $t=1$ 
through a negative wealth effect. Since $\frac{d c_{t}}{d i_{t}}>0$ under our parameterization where condition (13) holds, investment together with output and labor hours will fall as well at period 1. In sum, within the context of Eusepi's (2009) one-sector RBC economy, a positive news shock about future technological progress yields countercyclical responses of key macroeconomic aggregates that are qualitatively inconsistent with business cycles observed in the actual data (see Beaudry and Portier [2006]).

\section{Final Remarks}

To obtain further insights, we follow Beaudry and Portier (2004) and consider a generalized constant-relative-risk-aversion preference formulation in consumption. The household's period utility function now becomes

$$
U_{t}=\frac{c_{t}^{1-\sigma}-1}{1-\sigma}-\phi \frac{h_{t}^{1+\gamma}}{1+\gamma}, \quad \sigma>0, \quad \sigma \neq 1, \quad \gamma \geq 0 \quad \text { and } \phi>0,
$$

where $\sigma$ denotes the inverse of the intertemporal elasticity of substitution in consumption. In this case, it is straightforward to show that the analytical expression for $\frac{d c_{t}}{d i_{t}}$ is given by

$$
\frac{d c_{t}}{d i_{t}}=\frac{1}{\frac{y_{t}}{c_{t}}\left[\frac{\sigma(1-\alpha)(1+\eta)}{(1-\alpha)(1+\eta)-1-\gamma}\right]-1} .
$$

Equation (13) continues to be the necessary and sufficient condition for positive co-movement between consumption and investment when $\sigma>1$. However, it is only necessary for $\frac{d c_{t}}{d i_{t}}>0$ when $\sigma<1$. Although not shown here due to space limitation, we find that the impulse response functions with empirically plausible non-unitary values of $\sigma$ are qualitatively identical to those depicted in Figure 1. In particular, agents' rosy expectations about upcoming productivity growth generate a macroeconomic recession whereby output, consumption, investment and labor hours all fall in the announcement period. Overall, our analysis shows that under the maintained separability between consumption and labor hours in the household utility (cf. Jaimovich and Rebelo [2008, 2009] with non-separable preferences), news-driven business cycles do not arise in one-sector RBC models with aggregate increasing returns-to-scale in production; hence it remains an open research question as to under which condition(s) a onesector real business cycle model is able to generate qualitatively realistic cyclical fluctuations driven solely by agents' changing expectations about future economic fundamentals. 


\section{References}

[1] Beaudry, Paul and Franck Portier (2004), "An Exploration into Pigou's Theory of Cycles," Journal of Monetary Economics 51, 1183-1216.

[2] Beaudry, Paul and Franck Portier (2006), "Stock Prices, News, and Economic Fluctuations," American Economic Review 96, 1293-1307.

[3] Beaudry, Paul and Franck Portier (2007), "When can Changes in Expectations Cause Business Cycle Fluctuations in Neo-Classical Settings?" Journal of Economic Theory 135, $458-477$.

[4] Benhabib, Jess and Roger E.A. Farmer (1994), "Indeterminacy and Increasing Returns," Journal of Economic Theory 63, 19-41.

[5] Eusepi, Stefano (2009), "On Expectations-Driven Business Cycles in Economies with Production Externalities," International Journal of Economic Theory 5, 9-23.

[6] Jaimovich, Nir and Sergio Rebelo (2008), "News and Business Cycles in Open Economies," Journal of Money, Credit, and Banking 40, 1699-1711.

[7] Jaimovich, Nir and Sergio Rebelo (2009), "Can News about the Future Drive the Business Cycle?" American Economic Review 99, 1097-1118. 

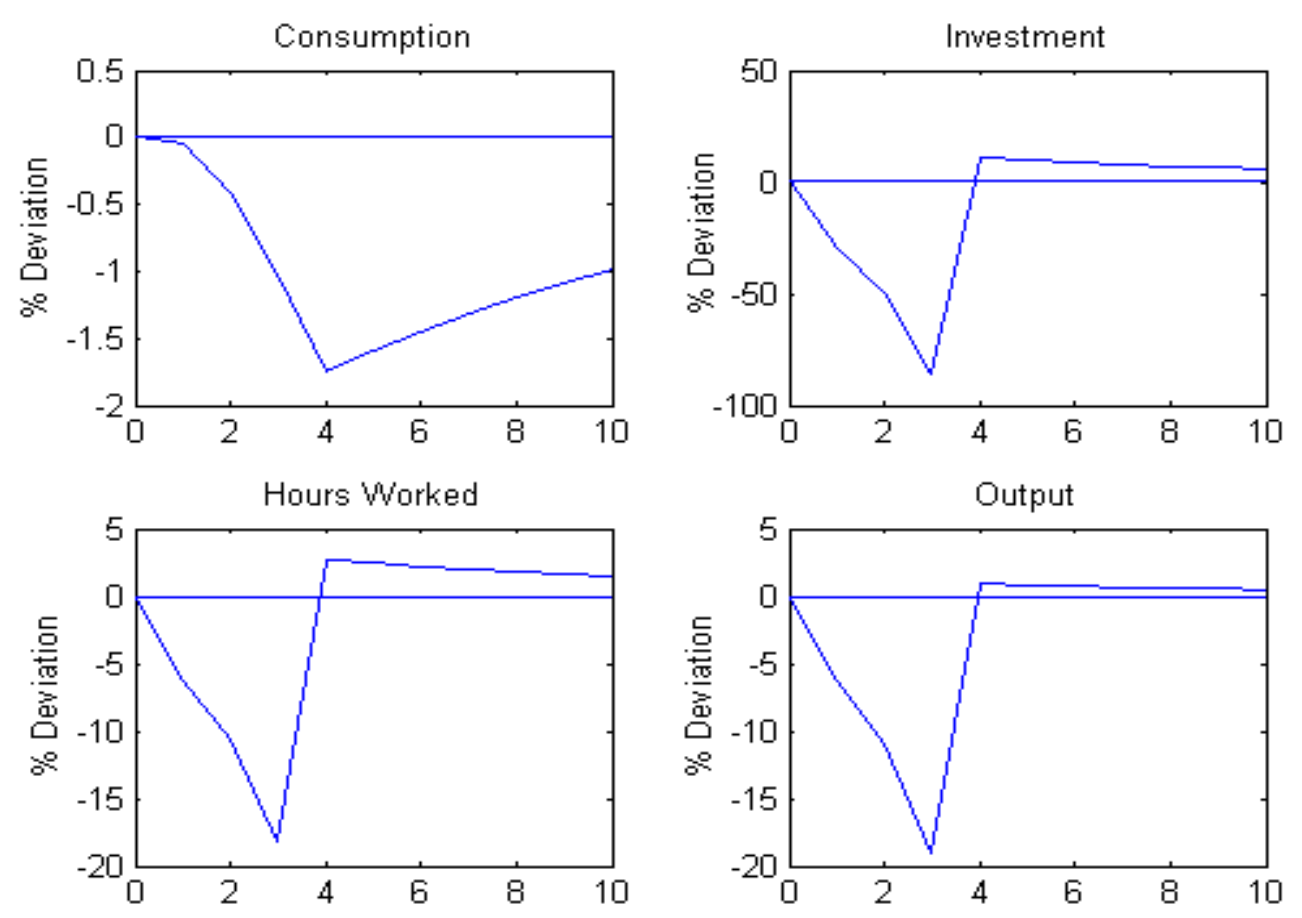

Figure 1: Impulse Response Functions

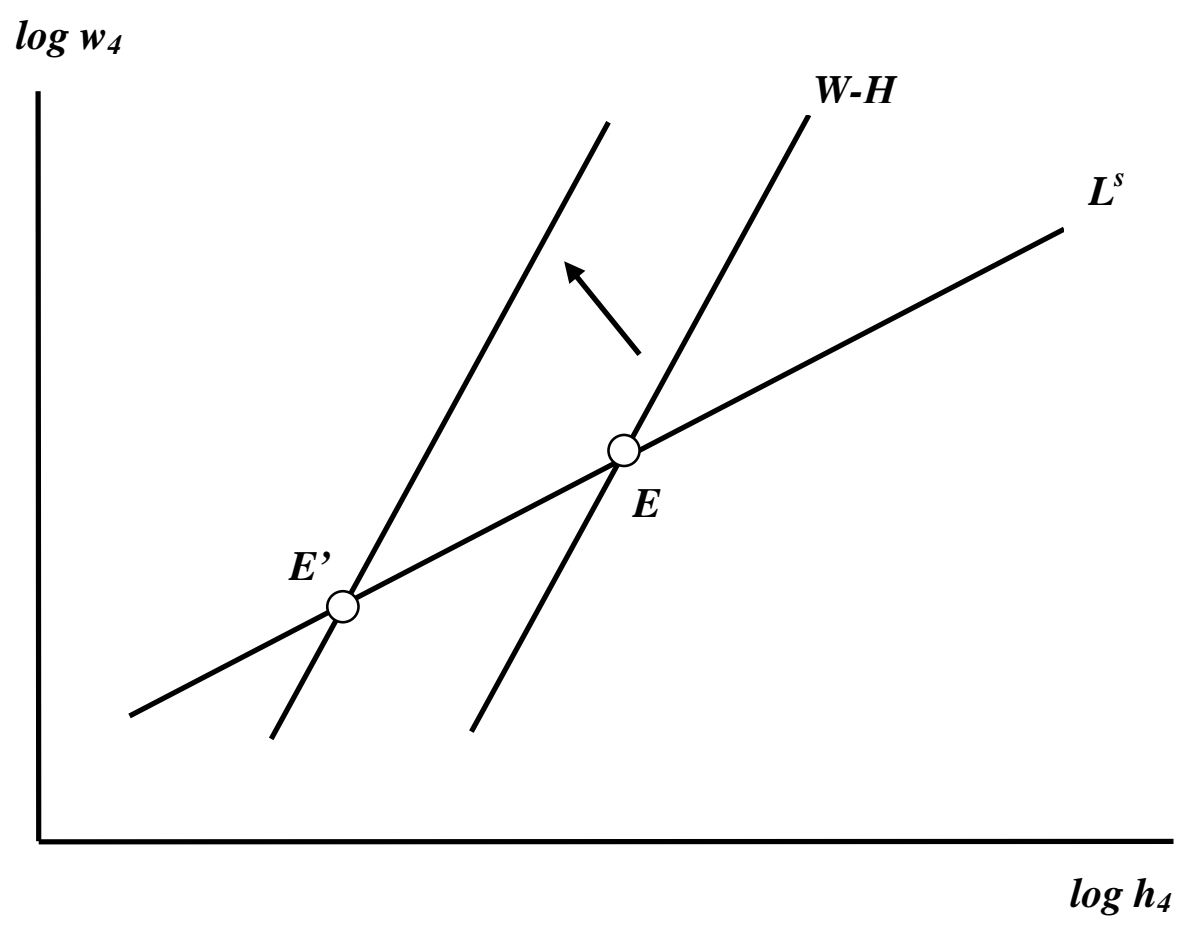

Figure 2: Anticipated Labor Market Outcomes at Period 4 